\title{
Study on the Nutritional Value Evaluation of Gramineous Grass in Natural Mowing Grasslands Based on Different Evaluation Models
}

\author{
Fanfan Zhang ${ }^{1}$, Lei $\mathrm{Yu}^{1,2}$, Chunhui $\mathrm{Ma}^{1}$, Weihua $\mathrm{Lu}^{1,2}$ \\ ${ }^{1}$ College of Animal Science \& Technology, Shihezi University, China \\ ${ }^{2}$ Key Laboratory of Oasis Ecology Agriculture of Xinjiang Production \& Construction Groups, \\ Shihezi University, China \\ zhangfangfang@163.com
}

Keywords: Natural mowing grasslands, Dominant gramineous grass, Evaluation models.

\begin{abstract}
This paper was designed to comprehensively and accurately obtain the order of nutritional value of the main dominant gramineous grass in the natural mowing grasslands in Shaertao Mountain. The nutrient content of the nine common species of gramineous grass in the natural mowing grasslands in Shaertao Mountain was analyzed. Four common evaluation models were used for nutritional value evaluation respectively, and a comprehensive analysis was carried out of their evaluation results. The results indicated that the order of nutritional value of the main dominant gramineous grass in the natural mowing grasslands in Shaertao Mountain from high to low was: Elymus nutans $>$ Roegneria sinkiangensis $=$ Dactylis glomerata $>$ Elymus cylindricus $>$ Brachypodium pinnatum $>$ Poa angustifolia $>$ Phleum phieoides $>$ Stipa capillatas $>$ Achnatherum splendens.
\end{abstract}

\section{Introduction}

Characterized by comprehensive analysis, evaluation models such as PCA (Principal Component Analysis), MFA (Membership Function Analysis), GRA (Grey Relational Analysis) and FSPRM (Fuzzy Similarity Priority Ratio Method) have been widely used in military, medical and agricultural fields, etc. However, different evaluation models can lead to different results in evaluating an object. Therefore, the four common evaluation models were employed in this study, and a comprehensive analysis was carried out of their evaluation results. The output of the integrated analysis was then applied in the nutritional value evaluation of the gramineous grass in the natural grasslands in Shaoertao Mountain in Xinjiang's Zhaosu County. This technique eliminated the differences resulting from individual evaluation models, providing more comprehensive and scientific evaluation results for the nutritional value evaluation of the main dominant gramineous grass in Shaertao Mountain.

\section{Natural Environment of Shaertao Mountain}

Shaertao Mountain is located in the northwest of Zhaosu County, Ili Kazakh Autonomous Prefecture, Xinjiang. It is a branch of the western Tianshan Mountains, and one of the main mountains forming Zhaosu Basin. The entire mountainous region stretches from east to west. The main body of the mountain borders Kazakhstan on the western and northern sides, and extends to the bank of the Tekes River in Zhaosu Basin on the southern side, with an altitude ranging from $1650 \mathrm{~m}$ to $3400 \mathrm{~m}$. The entire mountainous region is about $41.5 \mathrm{~km}$ from east to west and about $26 \mathrm{~km}$ to $28.0 \mathrm{~km}$ from north to south. Its geographic coordinate range is $80^{\circ} 15^{\prime}$ to $80^{\circ} 54^{\prime}$ east longitude and $42^{\circ} 54^{\prime}$ to $43^{\circ} 11^{\prime}$ north latitude. The average precipitation across the Piedmont region is about $450 \mathrm{~mm}$ and the precipitation in the middle and low mountains reaches above $580 \mathrm{~mm}$, with an average annual temperature of $2.9 \quad{ }^{\circ} \mathrm{C}$.

The natural mowing grasslands in this region are distributed in the middle and low mountains, and shallow valleys in the mountains, with the grassland vegetation mainly being mountain meadow made up of grass and forbs. Distributed at an altitude of $1800 \mathrm{~m}$ to $2300 \mathrm{~m}$, the grasslands 
are located in regions with maximum precipitation, where the weather is more humid. Mesophytic herbaceous plants grow well, with a variety of species and a high population density. The gross yield of the grasslands is generally $3161.91 \mathrm{~kg} / \mathrm{hm}^{2}$, with a grass height of $70-120 \mathrm{~cm}$ and grass coverage of above $85 \%$.

Experimental Materials. The experimental materials collected in this study are dominant gramineous grass in the vertical zones of natural grasslands in Shaertao Mountain, totaling nine species [1,2]. From piedmont plains, low mountains, to middle mountains, the dominant gramineous grass distributed is successively Achnatherum splendens (1650-1750m), Stipa capillata (1700-1900m), Poa angustifolia (1800-2000m), Elymus cylindricus (1800-2000m), Roegneria sinkiangensis (2000-2200m), Phleum phieoides (2000-2200m), Elymus nutans (2000-2300m), Brachypodium pinnatum (2000-2300m) and Dactylis glomerata (1800-2400m). General nutritional value analysis was carried out of the nine species of gramineous grass. The results are shown in Table 1.

Table 1 Nutrient content of dominant gramineous grass in Shaertao Mountain (\%DM)

\begin{tabular}{ccccccccc}
\hline Number & Species & Cash & CP & EE & NDF & ADF & Ca & P \\
\hline I & Achnatherum splendens & 5.75 & 5.91 & 0.95 & 90.5 & 43.5 & 1.70 & 0.07 \\
II & Stipa capillatas & 6.00 & 6.21 & 1.05 & 75.0 & 40.0 & 1.25 & 0.06 \\
III & Poa angustifolia & 5.75 & 9.19 & 0.90 & 62.0 & 34.0 & 1.30 & 0.08 \\
IV & Roegneria sinkiangensis & 6.25 & 13.83 & 0.95 & 65.0 & 38.0 & 2.00 & 0.06 \\
V & Elymus cylindricus & 7.50 & 7.70 & 1.05 & 58.5 & 38.0 & 1.95 & 0.06 \\
VI & Dactylis glomerata & 6.75 & 12.43 & 0.80 & 60.0 & 35.0 & 2.00 & 0.05 \\
VII & Elymus nutans & 5.00 & 5.78 & 1.03 & 59.5 & 34.5 & 1.50 & 0.18 \\
VIII & Phleum phieoides & 4.00 & 7.09 & 0.48 & 66.0 & 45.5 & 3.35 & 0.14 \\
IX & Brachypodium pinnatum & 8.75 & 6.96 & 1.35 & 65.0 & 48.5 & 1.85 & 0.06 \\
\hline
\end{tabular}

Note: Cash (Crude ash), CP (Crude Protein), EE (Ether Extract), NDF (Neutral Detergent Fiber), ADF (Acid Detergent Fiber), Ca (Calcium), P (Phosphorus).

\section{Application of Four Models in the Evaluation of Dominant Gramineous Grass Resources}

PCA (Principal Component Analysis) [3]. In principal component analysis, Formula (1) is the formula for calculating each principal component and Formula (2) is the calculation formula for the comprehensive principal component model. In Formula (1), $A$ is the value of an eigenvector and $Z$ is the standardized value of the nutritional indicator of each species of grass to be tested; In Formula (2), $\lambda_{i}$ represents the proportion of the variance contribution of the $\mathrm{i}^{\text {th }}$ principal component in the total variance contribution of the extracted principal components.

$$
F_{i}=\sum_{j=1}^{n} A_{i j} Z_{i j} \quad \mathrm{i}=1,2,3 \ldots \mathrm{n} \quad-(1) \quad F=\sum_{i=1}^{n} F_{i} \lambda_{i} \quad \mathrm{i}=1,2,3 \ldots \mathrm{n} \quad-(2)
$$

The seven nutritional indicators in Table 1 (CASh, CP, EE, ADF, NDF, Ca and P) were selected for principal component analysis. In order to eliminate the difference in dimensions, the seven indicators were standardized. ADF and NDF are two negative indicators, so reciprocals of the two sets of data for them were taken so that they were processed into positive indicators. SPSS software was used for principal component analysis (SPSS standardized data automatically) [4,5]. According to the principle that the eigenvalues of principal components should be greater than 1 , the original seven indicators were extracted as three uncorrelated principal components, with the total cumulative contribution rate being $83.681 \%$. The scores for the principal components were calculated according to Formula (1). After that, according to Formula (2), a comprehensive evaluation model was established as $\mathrm{F}=0.438 \mathrm{~F}_{1}+0.324 \mathrm{~F}_{2}+0.237 \mathrm{~F}_{3}$, where the greater the value of $\mathrm{F}$ is, the higher the nutritional quality is. The results are shown in Table 2. 
Table 2 Order of nutritional value of gramineous grass with PCA

\begin{tabular}{|c|c|c|c|c|c|c|c|c|c|}
\hline \multirow{2}{*}{ Projects } & \multicolumn{3}{|c|}{ Component } & \multirow{2}{*}{$\begin{array}{c}\text { Number of } \\
\text { Species }\end{array}$} & \multicolumn{3}{|c|}{ Component Scores } & \multirow{2}{*}{ Scores } & \multirow{2}{*}{ Rank } \\
\hline & 1 & 2 & 3 & & $\mathrm{~F}_{1}$ & $\mathrm{~F}_{2}$ & $\mathrm{~F}_{3}$ & & \\
\hline Cash & 0.901 & -0.007 & 0.241 & $\mathrm{I}$ & 0.044 & -2.122 & -0.104 & -0.693 & 9 \\
\hline $\mathrm{CP}$ & 0.129 & 0.715 & 0.587 & II & 0.121 & -0.321 & 0.837 & 0.147 & 4 \\
\hline $\mathrm{EE}$ & 0.874 & -0.182 & -0.315 & III & -0.921 & -0.003 & -0.160 & -0.443 & 8 \\
\hline NDF & -0.020 & 0.776 & -0.045 & IV & -0.038 & 0.957 & -0.722 & 0.122 & 5 \\
\hline $\mathrm{ADF}$ & -0.004 & 0.857 & -0.426 & $\mathrm{~V}$ & -0.387 & 0.858 & -0.660 & -0.048 & 6 \\
\hline $\mathrm{Ca}$ & -0.671 & -0.128 & 0.631 & VI & -0.603 & 0.552 & -0.440 & -0.189 & 7 \\
\hline $\mathrm{P}$ & -0.727 & -0.009 & -0.553 & VII & 2.227 & -0.552 & 0.406 & 0.893 & 1 \\
\hline The Eigenvalue & 2.571 & 1.898 & 1.388 & $\begin{array}{l}\text { VIII } \\
\text { IX }\end{array}$ & $\begin{array}{l}2.244 \\
0.027\end{array}$ & $\begin{array}{c}-1.234 \\
0.477\end{array}$ & $\begin{array}{l}0.000 \\
0.000\end{array}$ & $\begin{array}{l}0.583 \\
0.166\end{array}$ & $\begin{array}{l}2 \\
3\end{array}$ \\
\hline $\begin{array}{l}\text { of Component } \\
\text { The Cumulative }\end{array}$ & & & & $\begin{array}{l}\text { Contribution } \\
\text { rate } \%\end{array}$ & 36.731 & 27.117 & 19.833 & & \\
\hline $\begin{array}{c}\text { Contribution } \\
\text { Rate \% } \\
\end{array}$ & 36.731 & 63.848 & 83.681 & $\begin{array}{c}\text { Weight } \\
\text { coefficient \% }\end{array}$ & 43.807 & 32.405 & 23.701 & & \\
\hline
\end{tabular}

\section{MFA (Membership Function Analysis)}

In membership function analysis, Formula (3) is the formula for calculating the membership function value $U_{(x)}$, where $X$ is the measured value for the nutritional indicator of each species of gramineous grass, $U_{(x)}{ }^{+}$is the membership function value positively correlated to the nutritional value of grass, and $U_{(x)}{ }^{-}$is the membership function value negatively correlated to the nutritional value of grass.

$$
U_{(X)^{+}}=\frac{X_{i j}-X_{i \min }}{X_{i \max }-X_{i \min }} ; U_{(X)^{-}}=1-U_{(X)^{+}}
$$

Membership function analysis was carried out of the seven nutritional indicators (ADF and NDF are negative indicators) of each species of gramineous grass using Formula (3). The membership function values for the indicators were averaged for nutritional value evaluation. The higher the average is, the higher the nutritional value is. The results are shown in Table 3.

Table 3 Order of nutritional value of gramineous grass with MFA

\begin{tabular}{cccccccccc}
\hline $\begin{array}{c}\text { Number of } \\
\text { Species }\end{array}$ & Cash & CP & EE & NDF & ADF & Ca & P & Average & Rank \\
\hline I & 0.37 & 0.02 & 0.54 & 0.00 & 0.34 & 0.21 & 0.15 & $0.23 \mathrm{a}$ & 9 \\
II & 0.42 & 0.05 & 0.66 & 0.48 & 0.59 & 0.00 & 0.08 & $0.33 \mathrm{a}$ & 8 \\
III & 0.37 & 0.42 & 0.48 & 0.89 & 1.00 & 0.02 & 0.23 & $0.49 \mathrm{a}$ & 5 \\
IV & 0.47 & 1.00 & 0.54 & 0.80 & 0.72 & 0.36 & 0.08 & $0.57 \mathrm{a}$ & 2 \\
V & 0.74 & 0.24 & 0.66 & 1.00 & 0.72 & 0.33 & 0.08 & $0.54 \mathrm{a}$ & 4 \\
VI & 0.58 & 0.83 & 0.37 & 0.95 & 0.93 & 0.36 & 0.00 & $0.57 \mathrm{a}$ & 1 \\
VII & 0.21 & 0.00 & 0.63 & 0.97 & 0.97 & 0.12 & 1.00 & $0.56 \mathrm{a}$ & 3 \\
VIII & 0.00 & 0.16 & 0.00 & 0.77 & 0.21 & 1.00 & 0.69 & $0.40 \mathrm{a}$ & 7 \\
IX & 1.00 & 0.15 & 1.00 & 0.80 & 0.00 & 0.29 & 0.08 & $0.47 \mathrm{a}$ & 6 \\
\hline
\end{tabular}

Note: Different lower case letters within the same row show significant difference at 0.05 level. $F=0.802$

GRA (Grey Relational Analysis).For grey relational analysis, first of all, a reference sequence $X_{0}(k)$ was set, where $\mathrm{k}=1,2,3 \ldots \mathrm{n}$. The compared sequence is $X_{i}(k)$, where $k=1,2,3 \ldots \mathrm{n}$. The reference sequence is expected nutritional indicators while the compared sequence is the measured values for the indicators. The data were standardized according to Formula (4), where $X_{i j}{ }^{+}$ represents positive correlation with nutritional value and $X_{i j}{ }^{-}$represents negative correlation with nutritional value. Figure (5) is the formula for calculating the correlation coefficient $\xi_{i}(k)$, where $\Delta_{\mathrm{i}}(k)=\left|X_{0}(k)-X_{i}(k)\right|$, representing the absolute difference between the reference sequence $\mathrm{X}_{0}$ and 
the compared sequence $X_{i}$ at Point $k ; \Delta \min =\min \left[\min \Delta_{i}(k)\right]$, representing the minimum difference; $\Delta \max =\max \left[\max \Delta_{i}(k)\right]$, representing the maximum difference; and $\rho$ is the resolution coefficient, which generally takes 0.5 and considers equal importance. Figure (6) is the formula for calculating the weighted grey correlational degree, where $w_{i}$ is the weight of each indicator.

$$
\begin{aligned}
& X_{i j^{+}}=\frac{X_{i j}}{\max \left(X_{i j}\right)} ; X_{i j}=\frac{\min \left(X_{i j}\right)}{X_{i j}}-\text { (4) } \\
& \xi_{i}(k)=\frac{\Delta \min +\rho \Delta \max }{\Delta_{i}(k)+\rho \Delta \max }-(5) \quad r_{i}=\sum_{k=1}^{n} w_{i} \xi_{i}(k)-\text { (6) }
\end{aligned}
$$

Formula (4) was used to standardize the seven nutritional indicators of gramineous grass. Then, Formula (5) and Formula (6) were used to analyze weighted relational degree. The lower the weighted relational degree is, the closer the nutritional value of gramineous grass is to that of reference species and the higher its nutritional value is. The results are shown in Table 4.

Table 4 Order of nutritional value of gramineous grass with GRA

\begin{tabular}{cccccccccc}
\hline $\begin{array}{c}\text { Number of } \\
\text { Species }\end{array}$ & Cash & CP & EE & NDF & ADF & Ca & P & $\begin{array}{c}\text { Weighted } \\
\text { Relational } \\
\text { Degree }\end{array}$ & Rank \\
\hline I & 0.521 & 0.403 & 0.426 & 0.522 & 0.622 & 0.404 & 0.374 & 0.485 & 9 \\
II & 0.541 & 0.412 & 0.451 & 0.637 & 0.697 & 0.361 & 0.357 & 0.523 & 8 \\
III & 0.521 & 0.534 & 0.415 & 0.873 & 0.948 & 0.365 & 0.393 & 0.632 & 5 \\
IV & 0.564 & 0.991 & 0.426 & 0.795 & 0.757 & 0.438 & 0.357 & 0.653 & 3 \\
V & 0.708 & 0.465 & 0.451 & 1.000 & 0.757 & 0.432 & 0.357 & 0.647 & 4 \\
VI & 0.614 & 0.787 & 0.393 & 0.939 & 0.888 & 0.438 & 0.341 & 0.682 & 1 \\
VII & 0.468 & 0.399 & 0.445 & 0.958 & 0.917 & 0.384 & 0.807 & 0.667 & 2 \\
VIII & 0.412 & 0.442 & 0.338 & 0.773 & 0.590 & 0.714 & 0.568 & 0.565 & 7 \\
IX & 0.952 & 0.437 & 0.548 & 0.795 & 0.552 & 0.420 & 0.357 & 0.609 & 6 \\
Weight & 0.147 & 0.135 & 0.108 & 0.203 & 0.187 & 0.110 & 0.109 & & \\
coefficient & & & & & & & & & \\
\hline \multicolumn{6}{c}{}
\end{tabular}

\section{FSPRM (Fuzzy Similarity Priority Ratio Method) [6]}

The sum of the similarity number of the indicators between each species and the reference sample was obtained based on DPS software. The results showed that, the smaller the similarity was, the closer the nutritional value of this species of gramineous grass was to that of the reference grass and the higher nutritional value it had. The results are shown in Table 5.

Table 5 Order of nutritional value of gramineous grass with FSPRM

\begin{tabular}{cccccccccc}
\hline $\begin{array}{c}\text { Number of } \\
\text { Species }\end{array}$ & Cash & CP & EE & NDF & ADF & Ca & P & Similarity & Rank \\
\hline I & 6 & 8 & 4 & 8 & 6 & 4 & 4 & 40 & 8 \\
II & 5 & 7 & 2 & 7 & 5 & 7 & 5 & 38 & 7 \\
III & 6 & 3 & 5 & 4 & 1 & 6 & 3 & 28 & 4 \\
IV & 4 & 1 & 4 & 5 & 4 & 1 & 5 & 24 & 2 \\
V & 2 & 4 & 2 & 1 & 4 & 2 & 5 & 20 & 1 \\
VI & 3 & 2 & 6 & 3 & 3 & 1 & 6 & 24 & 3 \\
VII & 7 & 9 & 3 & 2 & 2 & 5 & 1 & 29 & 5 \\
VIII & 8 & 5 & 7 & 6 & 7 & 8 & 2 & 43 & 9 \\
IX & 1 & 6 & 1 & 5 & 8 & 3 & 5 & 29 & 6 \\
Weight & 0.147 & 0.135 & 0.108 & 0.203 & 0.187 & 0.110 & 0.109 & & \\
coefficient & & & & & & & & &
\end{tabular}




\section{Comprehensive Analysis of the Four Models}

Because the four evaluation methods differed in the evaluation of gramineous grass, and these differences were not only caused by the calculation methods of the evaluation models, but also were closely related to the selection of the weights of the various nutritional indicators. Therefore, in order to reduce the differences among different evaluation methods and make up the deficiency in the evaluation of a single evaluation model, the weighted scoring method was adopted to carry out a comprehensive analysis of the results for the various species of gramineous grass obtained through the four evaluation models. Fuzzy scoring was carried out in the order for each evaluation model $[7,8]$. The ranks are the scores. The lower the score is, the higher the nutritional value is. The weights of the four evaluation methods were set to be the same. The final results are shown in Table 6.

Table 6 Comprehensive Analysis of Four Models

\begin{tabular}{ccccccc}
\hline $\begin{array}{c}\text { Number of } \\
\text { Species }\end{array}$ & $\begin{array}{c}\text { PCA } \\
\text { Scores }\end{array}$ & $\begin{array}{c}\text { MFA } \\
\text { Scores }\end{array}$ & $\begin{array}{c}\text { GRA } \\
\text { Scores }\end{array}$ & $\begin{array}{c}\text { FSPRM } \\
\text { Scores }\end{array}$ & $\begin{array}{c}\text { Average } \\
\text { Scores }\end{array}$ & Rank \\
\hline I & 9 & 9 & 9 & 8 & 8.75 & 8 \\
II & 4 & 8 & 8 & 7 & 6.75 & 7 \\
III & 8 & 5 & 5 & 4 & 5.5 & 5 \\
IV & 5 & 2 & 3 & 2 & 3 & 2 \\
V & 6 & 4 & 4 & 1 & 3.75 & 3 \\
VI & 7 & 1 & 1 & 3 & 3 & 2 \\
VII & 1 & 3 & 2 & 5 & 2.75 & 1 \\
VIII & 2 & 7 & 7 & 9 & 6.25 & 6 \\
IX & 3 & 6 & 6 & 6 & 5.25 & 4 \\
\hline
\end{tabular}

\section{Conclusions}

The four evaluation models were combined to finally evaluate the nutritional value of the main dominant gramineous grass in the natural mowing grasslands in Shaertao Mountain. The order from high to low is: Elymus nutans $>$ Roegneria sinkiangensis $=$ Dactylis glomerata $>$ Elymus cylindricus $>$ Brachypodium pinnatum $>$ Poa angustifolia $>$ Phleum phieoides $>$ Stipa capillatas $>$ Achnatherum splendens. This evaluation result reveals the difference in nutritional value among these nine species of main dominant gramineous grass and provides a fundamental basis and theoretical foundation for the economic utilization of these gramineous grass resources.

\section{Acknowledgement}

This work was financially supported by the Special Fund for Agro-scientific Research in the Public Interest, China. Foundation Number: 201303062

\section{Reference}

[1] YU Lei. (2010). Natural Grassland and Forage Resources Atlas of Xinjiang Production and Construction Corps [M].Xinjiang People's Publishing House. (In Chinese)

[2] JIA Shen-xiu. (1997). Forage Floras of Chinese (Volume 1) [M].Chinese Agriculture Press. (In Chinese)

[3] ZHANG Dong-jie. (2011). Based on the Method of PCA to Forage Nutrition Evaluation of Qinghai Prefecture of Hainan Province, the Quality of the Natural Grassland Types [J]. Prataculture \& Animal Husbandry, NO.9:pp.11-14. (In Chinese) 
[4] ZHANG Yu. (2012). Application of SPSS Software and Principal Component Analysis Method in the Evaluation of Foraget Nutritive Value [J].Journal of Anhui Agricultural Sciences, 40(12):pp.7186-7188. (In Chinese)

[5] SHI Yong-hong, WAN Li-qiang, LIU Jian-ning, et al. (2010). Analysis of the Principal Components and the Subordinate Function of Lolium perenne Drought Resistance [J].Acta Agrestia Sinica,18(5):pp.669-672. (In Chinese)

[6] LU Wei-hua, YU Lei, LI Yan-xia. (2006). Production Evaluation of Different Alfalfa Varieties through Fuzzy Similarity Priority Ratio Method [J].Grassland and Turf, NO.3:pp.53-57. (In Chinese)

[7] HAO Li-zhuang, WANG Wan-bang, WANG Xun, et al. (2013). Evaluation of Nutritional Value and Carrying Capacity of Kobresia Grassland during the Period of Withered Grass in Sanjiangyuan Region[J].Acta Agrestia Sinica, 21(1):pp.56-64. (In Chinese)

[8] JIA Pin, LI Xiao-bin, WANG Jin-xiu. (2008). Comparison of Several kinds of Typical Comprehensive Evaluation Methods [J].Chinese Journal of Hospital Statistics, NO.4:pp.351-353. (In Chinese). 